\title{
Optical Properties of Modified CdSe Thin Films
}

\author{
PARESH SAHA*, JATINDRA NATH GANGULI and NILOTPAL SEN SARMA \\ Department of Chemistry, Gauhati University, Guwahati-781014, India \\ pareshsaha8@gmail.com
}

Received 26 April 2016/ Accepted 14 May 2016

\begin{abstract}
Thin film of CdSe has been deposited onto clean glass substrate by using Chemical Bath Deposition technique. For the as-deposited films, the XRD analysis revealed a uniform cubic phase of CdSe nanocrystalline thin film with preferred orientation along the (111) plane. Absorption spectra of this film have been recorded using spectrophotometer. The thickness of the film has been determined by gravimetric method. The energy band gap has been calculated using Tauc method. It is found that energy band gap of CdSe film is $2.35 \mathrm{eV}$.
\end{abstract}

Keywords: Thin film, Energy band gap, Gravimetric method

\section{Introduction}

Thin films of II-VI compounds have been widely investigated primarily because of their electronic, optical and optoelectronic applications. II-VI compound semiconductors have a band gap between 1-3 eV, which falls in the visible region and these semiconducting materials are used worldwide in optoelectronic devices. CdSe is one of such compound in this group and its physical properties have been constantly investigated during recent years for both fundamental and practical aims. It's interesting properties make them suitable for many potential applications in a variety of solid state devices such as solar cell, high efficiency thin film transistors, lightemitting diodes, electron-beam pumped lasers and electroluminescent devices etc. ${ }^{1-3}$.

In the recent years, major attention has been given to the investigation of optical and electrical properties of CdSe thin films in order to improve the performance of the device and also for finding new application ${ }^{4-8}$. These properties of CdSe are very sensitive to deposition condition and to the technique used. CdSe thin film has been prepared using a variety of methods including sputtering, spray pyrolysis, electrodeposition and thermal evaporation under high vacuum ${ }^{9,10}$. In view of this, the present study deals with preparation of CdSe thin films by Chemical Bath Deposition (CBD) method at room temperature under basic condition on glass substrates.

\section{Experimental}

Cadmium sulphate was purchased from LOBA Chemicals. 30\% ammonia solution and triethanolamine were procured from Merck. All chemicals were used as purchased. 
Sodium selenosulphate $\left(\mathrm{Na}_{2} \mathrm{SeSO}_{3}\right)$ was prepared by heating selenium powder with a solution of sodium sulphite $\left(\mathrm{Na}_{2} \mathrm{SO}_{3}\right)$ in water at $90{ }^{\circ} \mathrm{C}$ with constant stirring.

\section{Deposition of CdSe thin film}

A $30 \mathrm{~mL}$ of $0.5 \mathrm{M}$ cadmium sulphate $\left(\mathrm{CdSO}_{4}\right)$ solution was mixed with $30 \%$ ammonia solution. A white turbidity appears which was dissolved in excess of ammonia solution. After dissolving the turbidity $30 \mathrm{~mL}$ of $0.5 \mathrm{M}$ sodium selenosulphate was mixed with the solution. With this $30 \mathrm{~mL}$ triethanolamine was mixed with constant stirring. Then the solution was transferred to a $250 \mathrm{~mL}$ beaker in which glass plate were suspended horizontally. The system was kept at room temperature without disturbing. The thin film of CdSe was deposited on clean glass plate after 72 hours.

\section{Characterization}

UV-Vis spectra were recorded by using a U-4100 spectrophotomter (Hitachi). X-ray diffraction (XRD) patterns were recorded on SIEMENS D5005 $\mathrm{x}$-ray diffractometer with $\mathrm{Cu}$ $\mathrm{K} \alpha$ radiation. The thickness of the film was measured by weight difference method assuming the density of the deposited film to be same as that of the bulk. The film thickness varied with deposition time.

\section{Results and Discussion}

The thickness of the film in a single dipping was estimated by gravimetric method. According to gravimetric method the film thickness can be calculated as;

$$
\text { Thickness }(\mathrm{t})=\mathrm{M} / \mathrm{Ad}
$$

Where $\mathrm{M}=$ Mass of the thin film, $\mathrm{d}=$ Density of CdSe and $\mathrm{A}=$ Area of film. The value of density of $\mathrm{CdSe}=5.816 \mathrm{~g} / \mathrm{cc}$. Thus knowing the value of $\mathrm{M}, \mathrm{d}$ and $\mathrm{A}$ of the thin films, the thickness were calculated.

\section{XRD studies}

Figure 1 shows the XRD spectra of samples (prepared at temperature $30^{\circ} \mathrm{C}$ ). The XRD of the thin film was taken as prepared. It shows the characteristic peaks of CdSe at angles $25^{\circ}$, $42^{0}$ and $49^{\circ}$ which corresponds to diffraction from (111), (220) and (311) planes of ccp structure, the values agrees when compared with the Standard JCPDS data (file no.19-0191). The XRD pattern shows that the film is Polycrystalline in nature.

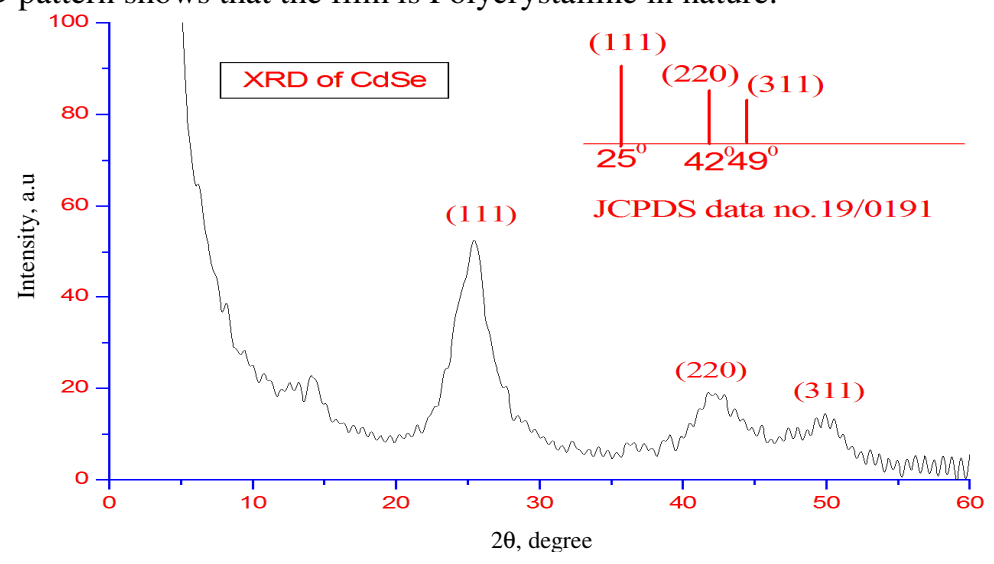

Figure 1. X-Ray diffraction pattern of CdSe 


\section{Optical properties}

The absorption spectra of CdSe thin film have been recorded over wavelength range 400 to $850 \mathrm{~nm}$ using a U-4100 spectrophotometer at room temperature. Figure 2 shows the absorption spectra of CdSe thin film. It is observed that the absorption coefficient is high at lower wavelength and decreases sharply below a certain wavelength for CdSe thin film. The energy band gap was determined using absorption spectra with the help of Tauc relation ${ }^{11}$. Using this relation, a graph was plotted between the square of ( $\alpha \mathrm{h} v)$ and $h v$ to obtain a straight line (Figure 3). The extrapolation of straight line to $(\alpha \mathrm{hv})^{2}=0$ axis gives the value of the band gap. The energy band gap of this sample is $2.35 \mathrm{eV}$. It is in well agreement with the value reported elsewhere ${ }^{12}$.

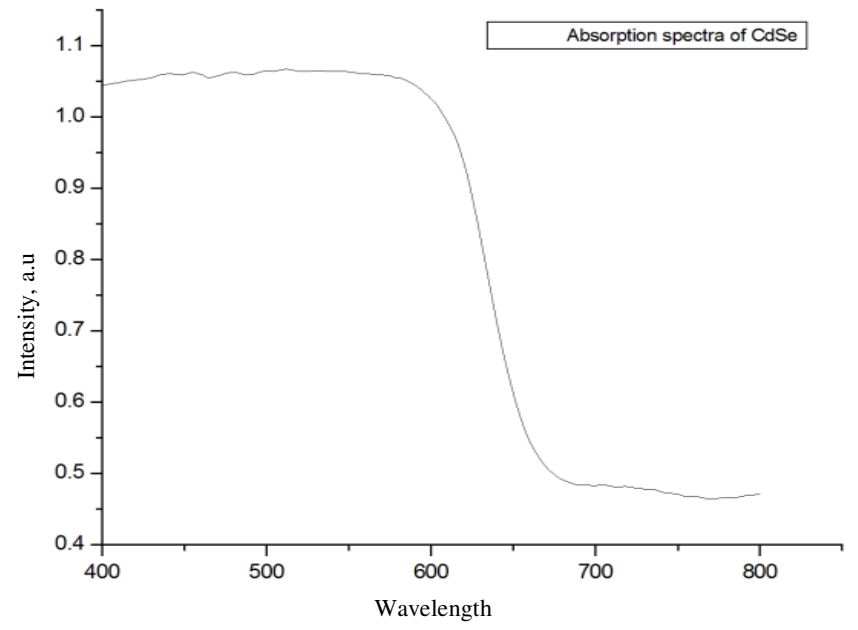

Figure 2. Absorption spectra of CdSe thin film

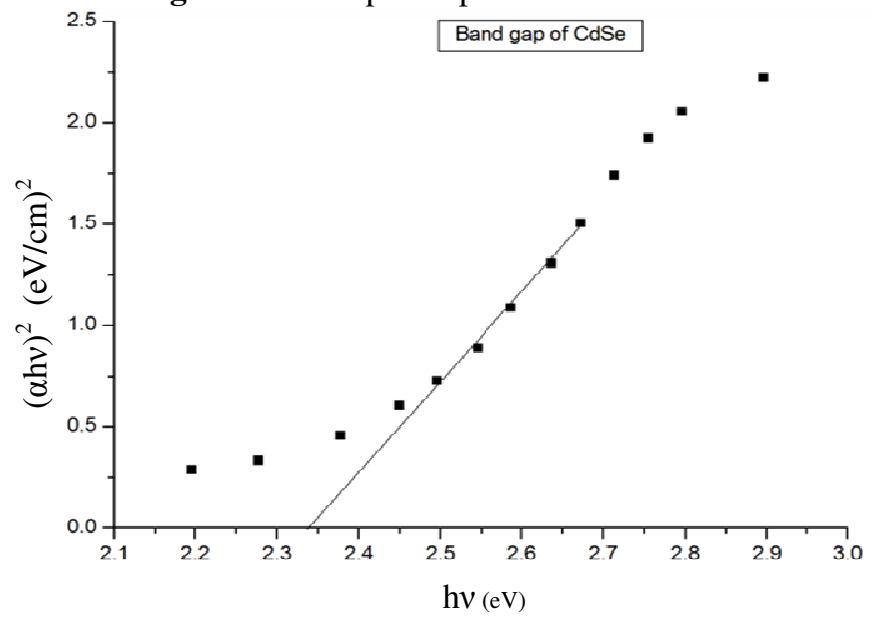

\section{Conclusion}

Figure 3. Plot of hv vs. $(\alpha h v)^{2}$ for as-deposited CdSe thin film

CdSe thin film had been synthesised by chemical bath deposition method, which is easy and low cost technique. CdSe film grows preferentially along a-direction. The energy of band gap is lie within the ranges of semiconductor. 


\section{Acknowledgement}

The authors are grateful to Gauhati University, Assam for the assistance for this work.

\section{References}

1. Bouroushian M, Loizos Z, Syrellis N and Maurin G, Thin Solid Films, 1993, 10(2), 229-242; DOI:10.1016/0040-6090(72)90190-3

2. Shaw G A and Parkin I P, Inorg Chem., 2001, 40, 6940-6947; DOI:10.1021/ic010648s

3. Baban C, Rusu G I and Prepelita P, J Optoelectronics Adv Mater., 2005, 7(2), 817-821.

4. Oduor O and Gould R D, Thin Solid Films, 1995, 270(1-2), 387-390; DOI:10.1016/0040-6090(95)06930-5; 1998, 317(1-2), 409-412; DOI:10.1016/S00406090(97)00575-0

5. Mohanchandra K P and Uchil J, Thin Solid Films, 1997, 305, 124-129; DOI:10.1016/S0040-6090(97)00188-0; J Appl Phys., 1998, 84(2), 306; DOI:10.1063/1.368028

6. Lee M J and Shis-Chung Lee, Solid State Electronics, 1999, 43(4), 833-838; DOI:10.1016/S0038-1101(99)00007-6

7. Samanta D, Samanta B, Chaudhuri A K, Ghorai S and Pal U, Semicond Sci Technol., 1996, 11, 548-553.

8. U. Pal, D. Samata, S. Ghorai, A K Chaudhuri, J Appl Phys., 1993, 74(10), 6368-6374; DOI:10.1063/1.355161

9. Chopra K L and Das S R, Thin Film Solar Cells (Plenum Press, New York-London, 1983), 143-150.

10. Rouleau C M and Lowndes D H, Appl Surf Sci., 1998, 127-129, 418-424; DOI:10.1016/S0169-4332(97)00666-1

11. Froment $\mathrm{M}$ and Lincot D, Electrochim Acta, 1995, 40(10), 1293-1303; DOI:10.1016/0013-4686(95)00065-M

12. Cullity B D, Elements of X-ray diffraction, Addison Wesley, Massachusetts, London, 1959. 